\title{
Is whole-body vibration beneficial for seniors?
}

\author{
C. Lachance $\cdot$ P. Weir $\cdot$ K. Kenno $\cdot$ S. Horton
}

Received: 5 January 2011 / Accepted: 12 December 2011 / Published online: 6 January 2012

(C) European Group for Research into Elderly and Physical Activity (EGREPA) 2012

\begin{abstract}
Normal aging processes result in losses of functional flexibility and muscular strength, which increase seniors' fall risk and dependence on others. A relatively new intervention to reduce and/or reverse the adverse effects of aging is wholebody vibration (WBV) exercise. The purpose of this article is to review the established effects of WBV exercise exclusively with the aging population. A systematic search utilizing PubMed and Sport Discus databases uncovered journal articles specific to seniors and whole-body vibration. An extensive hand search supplemented the database results to find other relevant articles. Twenty-seven articles were obtained; all articles have been published in the past 8 years, reflecting the recent and growing interest in this area. Researchers have determined that WBV training can reduce fall risk and improve postural control in seniors. It has also been determined that WBV training can be as effective as conventional resistance training to improve seniors' lower body strength. However, little is known about the effect of WBV exercise on flexibility and upper body strength in the aging population. More research is required to establish how effective WBV training is on these specific components and how it may affect seniors' quality of life.
\end{abstract}

Keywords Whole-body vibration · Aging - Vibration exercise $\cdot$ Muscle strength $\cdot$ Postural control $\cdot$ Flexibility

\section{Introduction}

Over the last century, life expectancy has increased dramatically to the point that individuals in developed nations can expect to

C. Lachance $(\bowtie) \cdot$ P. Weir $\cdot$ K. Kenno $\cdot$ S. Horton

Department of Kinesiology, University of Windsor,

Windsor, ON, Canada

e-mail: lachancc@uwindsor.ca

e-mail: chantelle.lachance@gmail.com live beyond 80 years of age $[16,17,22,32]$. With continuing advancement in medical technology and baby boomers approaching mid-to-late adulthood, the aging population is steadily increasing. Seniors aged 65 and older will soon comprise a massive proportion of the global population, growing to an estimated 690 million in developed countries by 2030 from 249 million in 2000 [46]. Governments and private funding agencies have recognized that seniors will be a large portion of the general population and have increased age-related funding initiatives [21]. The goal of these initiatives is to further understand the mechanisms of aging so effective strategies can be developed for treating age-related ailments, maintaining seniors' independence, reducing risk factors, and improving activities of daily living [21].

\section{Slips and falls}

Slips and falls are a common occurrence in the aging population [26]. Approximately $30 \%$ of the community-dwelling population over 65 years of age falls at least once a year [26, 50 ]. Of those who fall, $50 \%$ will never regain functional walking [31]. This high prevalence of seniors falling puts a substantial financial burden on national governments. For example, the Canadian government spends 2.4 billion dollars per year (one billion in direct costs) because of the injuries and rehabilitation that are associated with seniors' falls [50].

Musculoskeletal integrity is a major reason why seniors are more susceptible to falling $[3,15]$. Recently, researchers have examined skeletal muscle to better understand how it deteriorates with age in order to determine methods of reversing its adverse effects and reducing seniors' risk of falling $[16,17,21,30]$.

Sarcopenia has been identified as the normal age-related loss of muscle mass and strength [22]. Typical sarcopenic 
characteristics include reduced muscle mass, a shift in fibertype distribution, a loss of force-generating capacity, and reduced ability to effectively perform activities of daily living [22]. Cross-sectional research has demonstrated that skeletal muscle mass noticeably decreases by 45 years of age, and declines by $0.5-1 \%$ per year thereafter [21]. Lexell [25] found that limb muscles of older men and women are $25-35 \%$ smaller than younger individuals. When biopsies were compared between the young and old participants, type II (fast twitch) fibers and to a lesser extent type I (slow twitch) fibers were smaller in the older participants, reducing the ability to produce strong muscular contractions [25]. Lexell [25] concluded that with advancing age, there is a gradual decrease in muscle fiber size and volume, which is accompanied by a replacement with fat and connective tissue. Most of these changes are a primary consequence of aging which can be delayed in the elderly with increases in physical activity.

\section{Resistance training}

A loss in muscle mass and strength influences the prevalence of falls, thereby reducing the quality of life and perhaps decreasing longevity in seniors [22]. Leigh [24] emphasized the need for nonpharmacological intervention to help reduce fall risk factors. Since aging does not alter the skeletal muscle response to strength training, resistance training (e.g., free weights, exercise machines, rubber bands) is currently the most effective known strategy to combat sarcopenia and increase strength [22]. However, resistance exercise programs may not be feasible with seniors who have mobility and/or neurological impairments [45].

\section{Whole-body vibration}

Whole-body vibration (WBV) has shown potential as an alternative form of strength training. WBV has benefits over conventional resistance exercise as it generally requires less time and effort [43], yet evidence suggests it is as effective as conventional training [41]. WBV training normally consists of performing static and/or dynamic exercises on a vibrating platform [27]. There are two common forms of vibration platforms: synchronous vibration or side altering vibration [34]. Synchronous platforms have a vertical or up and down vibration stimulus $[10,27,34]$ and side altering vibration platforms deliver an asynchronous vibration (teeter totter) stimulus as the platform balances around a central fulcrum $[27,34,39]$. WBV apparatuses vary in terms of frequency (in hertz) they can produce and the magnitude of vibration. While researchers have used both "amplitude" and "peak-to-peak displacement" to describe the magnitude of vibration, the latter (peak to peak) is the recommended term, which is the total vibration excursion of a point (in millimeters) between its positive and negative extremes [27, 34].

Typically the vibrations are transmitted through the legs to the body, stimulating the neuromuscular system [41]. With each vibration the platform shifts slightly downward (vertical displacement $\sim 1-10 \mathrm{~mm}$ ), lengthening the tendon resulting in an involuntary contraction $[3,10]$. The platform then shifts back to its initial position and repeats (normal frequency range is $15-60 \mathrm{~Hz}$ ) [10]. By the WBV platform providing both physical and neural overloads, it causes the body's skeletal and neural tissues to adapt [43]. Pairing WBV with a common task, such as a squat, has been reported to increase electromyographical activity, strength, power, balance and postural control in the muscles being trained [43]. Although there are several proposed theories that attempt to explain how WBV enhances muscle function (e.g., neural potentiation of the stretch reflex [40] and muscle tuning hypothesis [10]), the biological mechanisms elicited due to WBV remain equivocal and require further investigation.

\section{Whole-body vibration studies among the aging population: targeting specific needs}

Initially, WBV training studies examined primarily young and athletic participants. More recently WBV research has been applied to a wide variety of populations, including the young and old, fit and unfit, and healthy and pathological participants (e.g., $[6,24,29,45])$. A search was conducted using electronic databases PubMed and Sport Discus using the following combination of search words: (whole-body vibration OR vibration training OR vibration exercise) AND (elder* OR ag* OR senior). There was no time restriction on the literature search, performed in April 2011, which resulted in a total of 139 journal articles. Articles were checked for relevant content and were included if they were published in English and used participants aged 55 and older. Review articles, duplicates, and studies that used locally applied vibration and/or used animals as test participants were excluded. An extensive hand search supplemented the database results to find other journal articles specific to seniors and WBV. Potential articles were retrieved and read to attain three additional WBV aging studies. While other review articles have included WBV and aging as part of a larger context, this paper focuses solely and exclusively on WBV as it applies to the older population. Thus, the search uncovered 27 journal articles, which are compiled and summarized in Table 1. This table draws upon and builds on Rehn et al. [38] and Totosy de Zepetnek et al. [44], but is specific to WBV within an older population. Table 1 identifies each study's specific objectives, design (i.e., randomized controlled study), and whether the participants were institutionalized or noninstitutionalized. In addition, Table 1 identifies the WBV 
plate and parameters, ${ }^{1}$ exercises performed, along with measurements and results specific to each study. All 27 studies have been published in the last 8 years, reflecting the recent and growing interest in this area. This is an opportune time to provide an overview of the research and provide direction for future areas of investigation.

\section{Balance and fall prevention}

Thirteen published articles discussed the effects of WBV on seniors' postural control and balance. Twelve of the articles showed significant benefits of using WBV to improve balance and/or postural control, while one showed no significant improvement [11]. A potential limitation of the Carlucci et al. [11] study was that their intervention consisted of one session of WBV. The articles that show significant results suggest WBV can improve elements of fall risk and improve postural control $[1,8,13,23,37]$.

In an attempt to decrease fall risk and improve healthrelated quality of life in nursing home residents, Bruyere and colleagues [8] investigated the effects of WBV on 42 seniors who resided in a nursing home. Participants were randomized to receive physical therapy alone or physical therapy plus a WBV intervention. Physical therapy consisted of a standard exercise program with components of balance and gait training along with strengthening exercises. The experimental group participated in three sessions of WBV training per week for 6 weeks. A typical session involved the participant standing on the vibration platform for $1 \mathrm{~min}$ of vibration stimulus four times, with $90 \mathrm{~s}$ of rest between sets.

The Tinetti Test consists of 16 test variables used to assess balance and gait, as it grades gait speed, stride, symmetry, and balance. Each component of the test was graded from 0 to 1 or 0 to 2 (the lower score indicates poorer physical ability), with the highest possible overall score on the test being 28 . The test was performed on each participant at baseline and after 6 weeks of training. The overall score of the Tinetti Test increased by $5.6 \pm 3.7$ points in the WBV experimental group vs. the physical therapy only group, which actually decreased $0.1 \pm 1.3$ points after 6 weeks. This suggests that combining WBV exercise with physical therapy is more effective at improving gait and balance as measured by the Tinetti Test than physical therapy alone and, therefore, may reduce nursing home residents' risk of falling [8].

\footnotetext{
${ }^{1}$ The reader should be cautioned that there has been inconsistent use of the words amplitude and peak-to-peak displacement in the literature [27]. Although peak-to-peak displacement is the recommended term, both are still used in research articles. Therefore, the values in the chart may be either of the two terms peak-to-peak displacement or amplitude. Caution is warranted here, particularly as researchers themselves have occasionally confused the two terms [27].
}

In a separate study, Kawanabe and colleagues [23] found that after 2 months of training, WBV in addition to routine exercise (walking, balance training, and muscle strengthening) significantly improved maximum standing time on one leg. The group that only performed routine exercises did not show any significant improvement with maximum standing time, suggesting adding WBV exercise to an exercise regimen can improve selected balance tasks [23].

Rees et al. [37] conducted a 2-month trial in an attempt to delineate the direct effects of WBV by randomly assigning 43 participants (66-85 years) into three groups: a WBV group, an exercise without WBV group, and a control group. The study was designed to determine the effectiveness of WBV exercise on postural steadiness by evaluating 8 weeks of standard WBV exercise with respect to the same program performed without vibration [37]. Both exercise groups performed static squats for the first 4 weeks and dynamic squats and dynamic calf raises for the last 4 weeks of training, the key difference being that the WBV group performed all of the exercises on a vibration platform.

To determine the effectiveness of WBV on postural steadiness, all participants were assessed by analyzing patterns of ground reaction force variability via a one-legged postural steadiness (OLPS) test. The OLPS starting position had the participant stand with feet shoulder width apart, with their eyes looking forward. The investigator then instructed the participant to stand freely on one leg for a maximum of $15 \mathrm{~s}$. Three consecutive trials of OLPS were performed on both legs of all participants; however, only the results for the right leg were reported. Results indicated WBV improved OLPS between $24.9 \%$ and $27.5 \%$, on average following 8 weeks of WBV exercise. There were no significant differences found pre- to posttest for the exercise without WBV group or the control group. Of interest was the fact that individuals with the largest improvements were those with the worst baseline scores; thus, the authors postulated that those with very poor balance are the ones most likely to derive the largest benefits from a WBV intervention [37].

\section{Lower extremity power and strength}

Fourteen studies examined muscular power and/or strength while using WBV. A pilot study examining polio patients was the only study that did not show increased strength benefits with WBV training [7]. For the remaining 13 articles specific to lower body strength, two main themes exist; WBV improves muscular strength in seniors (e.g., [2, 28, 49]), and WBV is as effective as conventional resistance training (e.g., $[35,41])$.

To determine if WBV improved seniors' muscular power, Russo and colleagues [42] recruited 29 postmenopausal women who were randomly assigned to a WBV group or 


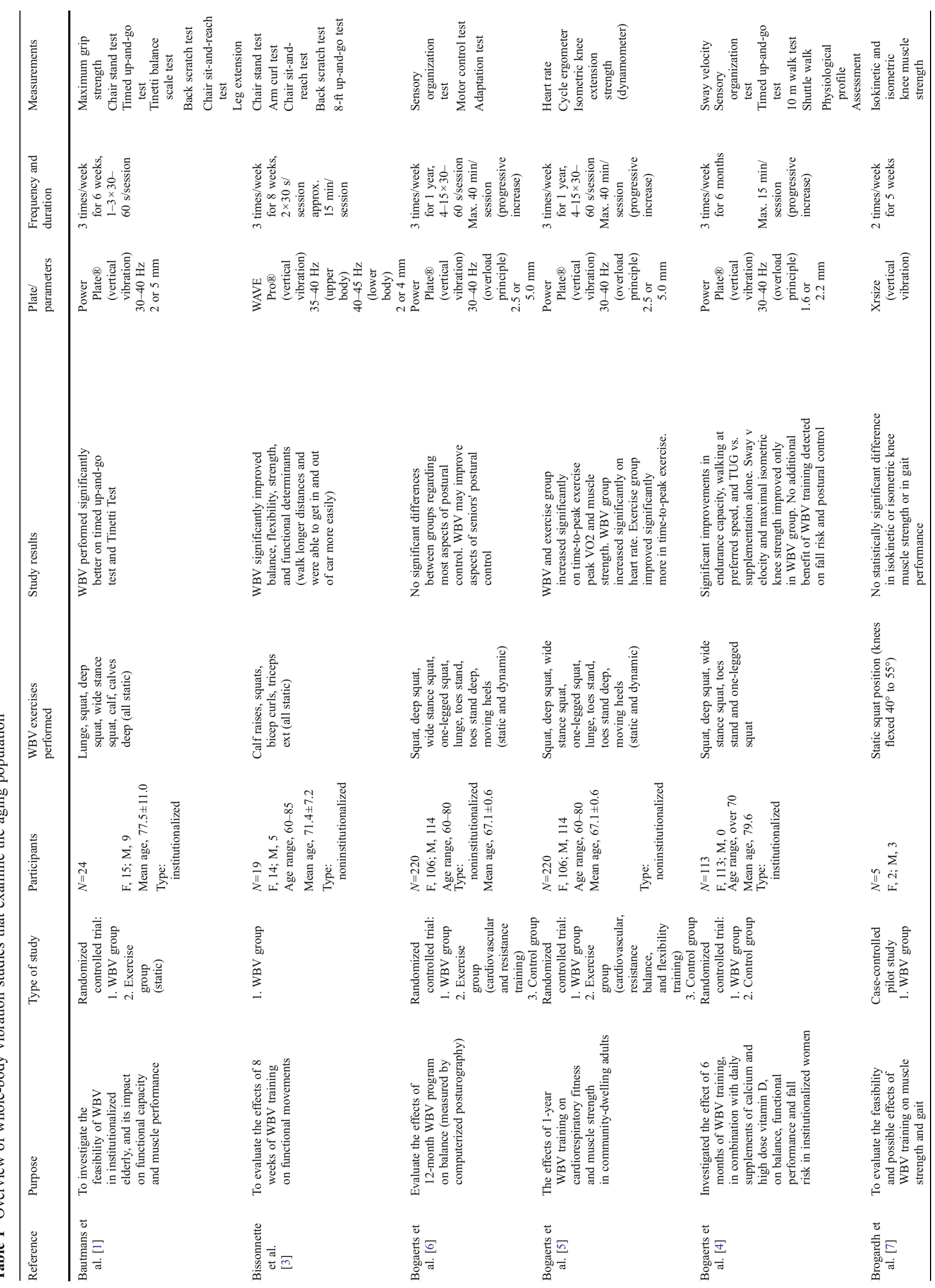




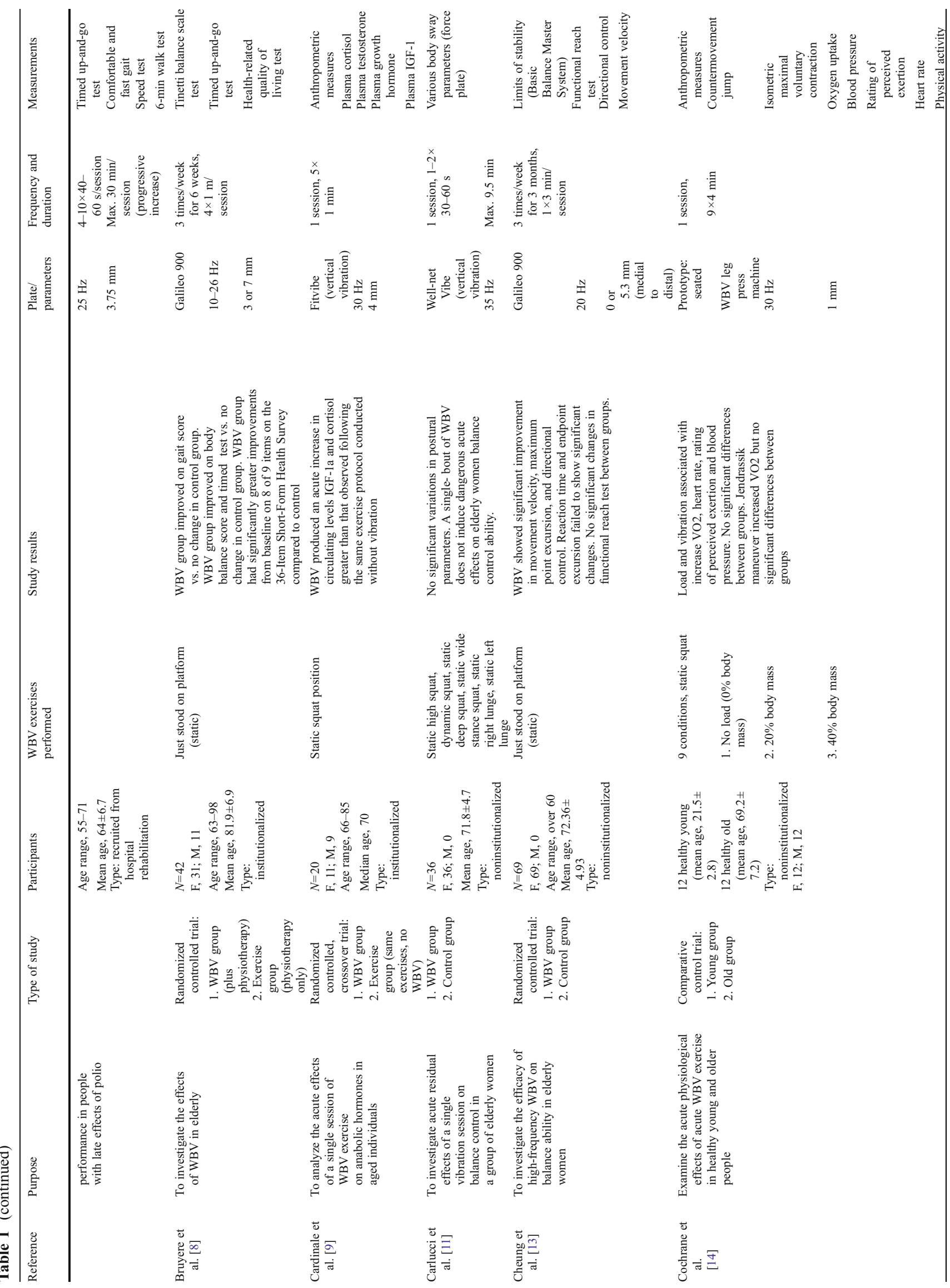




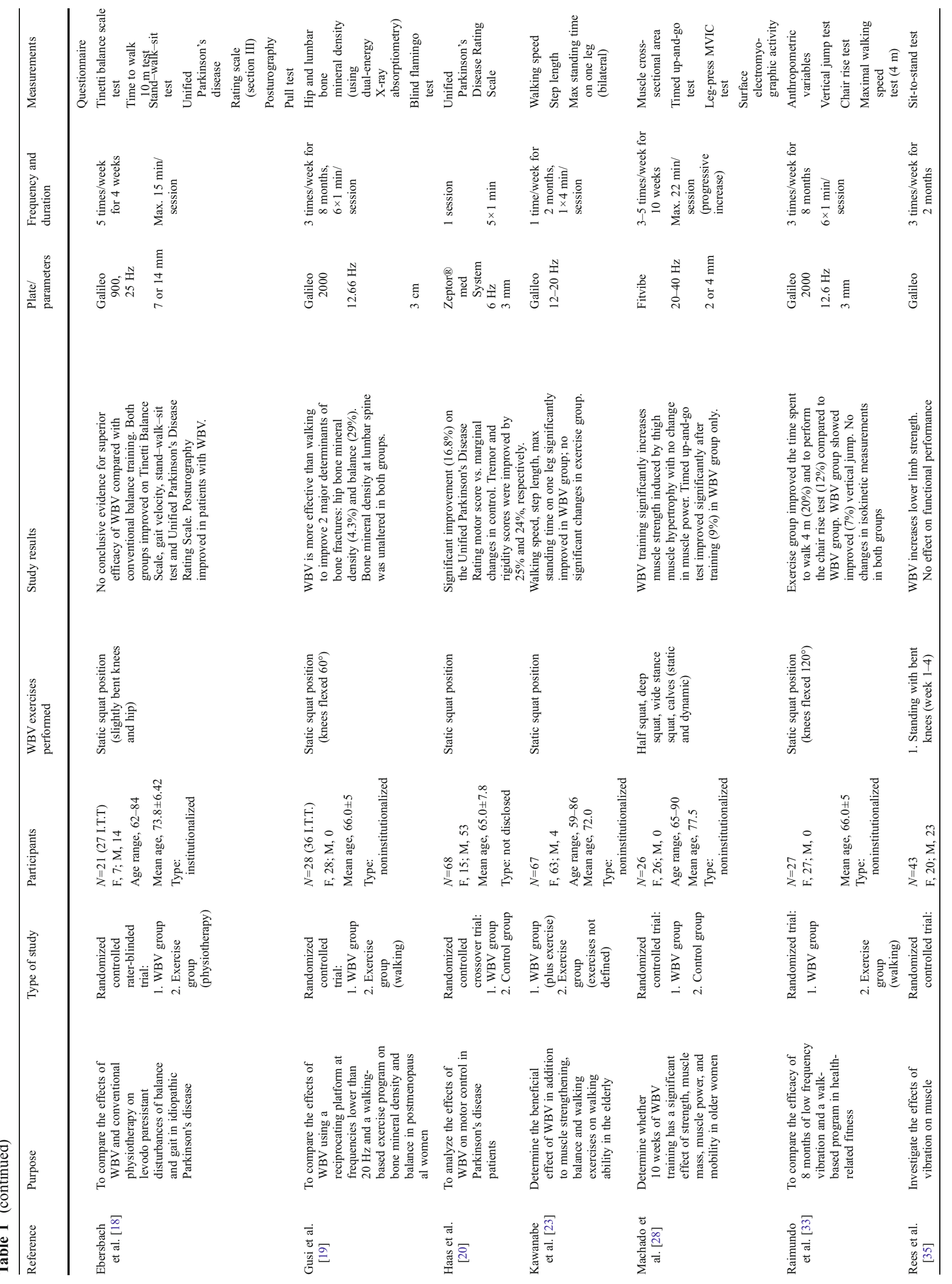




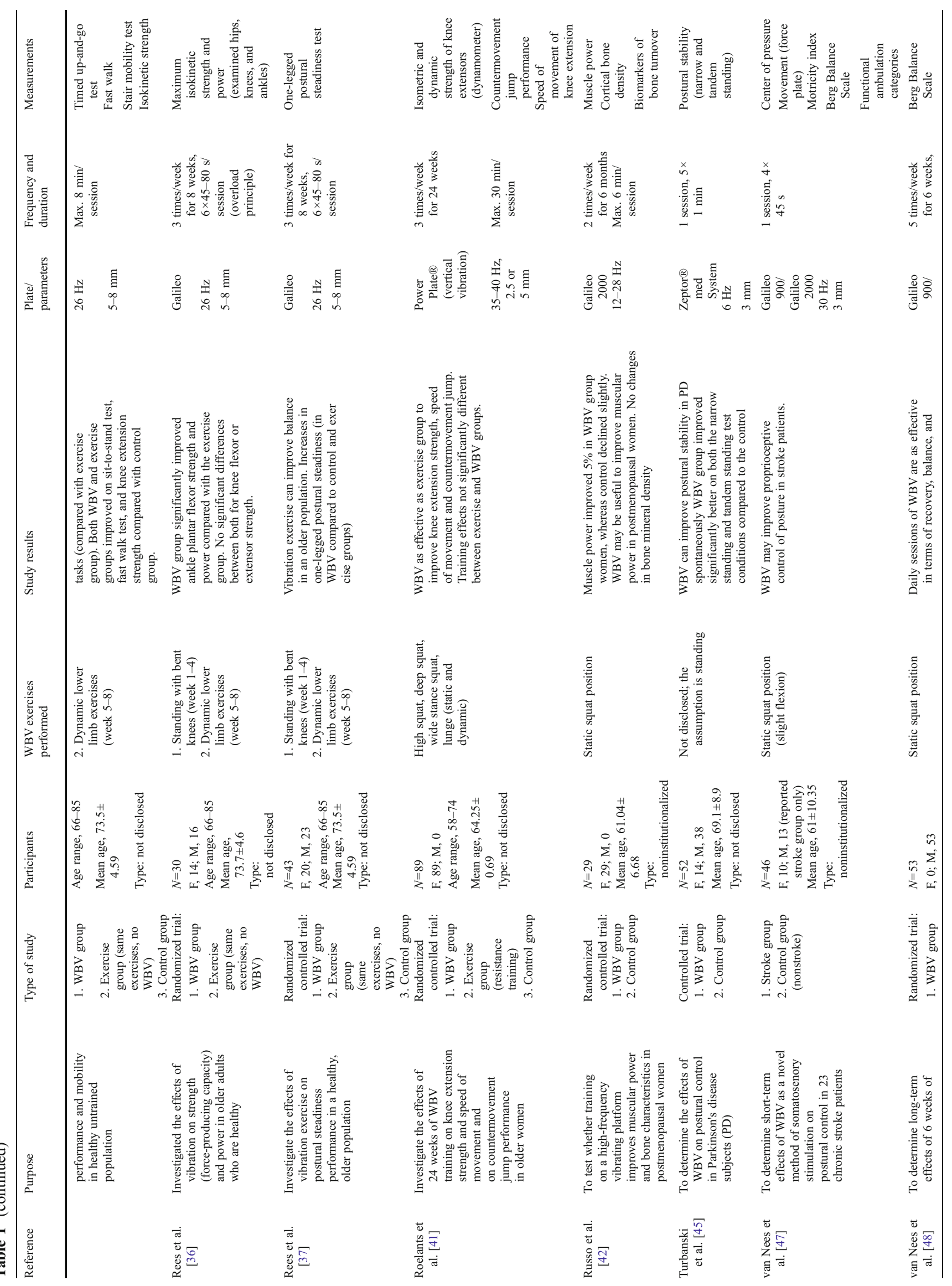




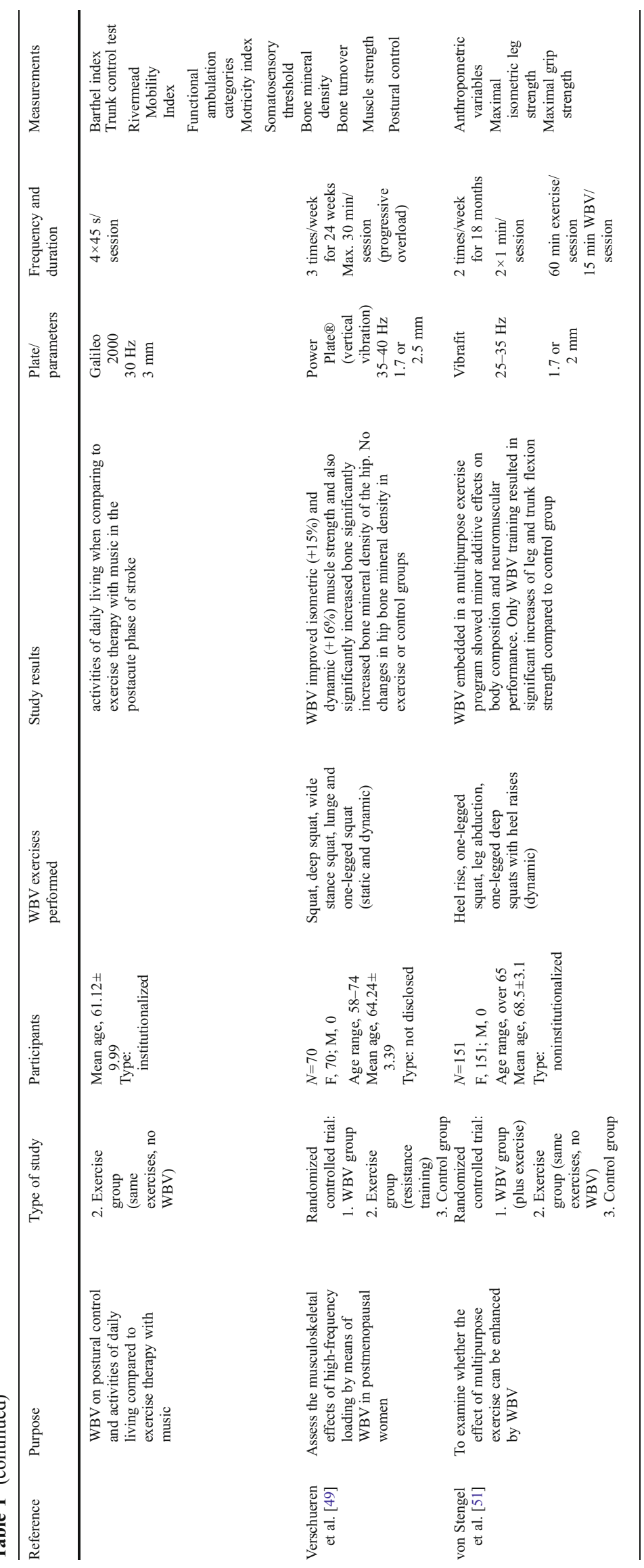


a control group. The WBV group stood on the WBV platform with their knees slightly bent for three 2-min sessions twice a week, for 6 months. The control group did not receive any training. Muscular power was quantified by measuring participants' ground reaction forces from jumps on a force plate. After 6 months, muscle power improved $5 \%$ in women who received WBV training, whereas the control group declined slightly. This suggests that WBV may be useful for improving muscular power in postmenopausal women [42].

Verschueren et al. [49] investigated postmenopausal women to determine if WBV training would improve muscular strength. Seventy women (58-74 years) were randomly divided into three groups: WBV training group (WBV), exercise without vibration group, and a control group. Baseline measures were taken for all participants to determine initial isometric and dynamic strength. The WBV and exercise group trained three times per week for 24 weeks; the WBV group performed various static and dynamic lower body exercises on the vibration platform, while the exercise group trained their lower body by leg extension exercises and dynamic leg presses. After training, isometric strength of the knee extensors increased in both WBV and exercise groups, by $15 \%$ and $16 \%$, respectively. Dynamic strength increased by $16.5 \%$ in the WBV group and $10.6 \%$ in the exercise group. The controls showed no significant change in isometric and dynamic strength from pre- to posttest [49]. These results are consistent with Roelants et al. [41], who had parallel results with 89 postmenopausal women. Both studies suggest WBV can significantly improve dynamic and isometric strength in postmenopausal women. Roelants and colleagues [41] also proposed WBV was as effective as conventional resistance training when testing knee extension strength, speed of movement of knee extension (the highest possible speed the participant could extend their knee from $90^{\circ}$ to $160^{\circ}$ ), and countermovement jump performance (flight time of a concentric muscle contraction following an eccentric muscle contraction) in older women [41].

To determine if WBV training has a significant effect on both muscular strength and power, Machado et al. [28] randomly assigned 26 senior women (65-90 years) to either a WBV training group or a control group. The WBV group trained for 10 weeks on the WBV platform performing calf raises and various squatting exercises, after which participants were compared to their baseline measurements. The WBV group had increases in maximum voluntary isometric contraction (MVIC-38.8\%) as well as increases in the cross-sectional area of both the vastus femoris $(8.7 \%)$ and biceps femoris muscles $(15.5 \%)$. No changes were detected in the control group. Muscle power with an external resistance of $20 \%, 40 \%$, and $60 \%$ MVIC decreased from pre- to posttest only in the control group; the authors concluded that WBV training prevented the decrease in muscular power in the WBV group. These results further suggest that WBV can improve muscular strength in older women, which Machado et al. [28] attributed to thigh muscle hypertrophy.

\section{Flexibility}

Bautmans and colleagues [1] were the first researchers to test an element of flexibility training with WBV in seniors. Twenty-four nursing home residents ( 9 male and 15 female) were randomly selected to either a WBV group or a control group. Participants from both groups were examined on flexibility pre- and posttest utilizing the chair sit-and-reach test (lower body flexibility) and the back scratch test (upper body flexibility). The WBV group performed lunges along with various types of squats and calf raises on a vibration platform, which target all the lower limb muscles. After 6 weeks, lower body flexibility improved significantly in the WBV group, indicating that general exercises may benefit flexibility. No significant differences were found in upper body flexibility pre- to posttest in either group, which may be attributed to participants not performing any exercises that targeted the upper body specifically [1].

Similarly, Bissonnette et al. [3] examined upper and lower extremity flexibility using the same protocol. Nineteen participants (60-85 years) performed the chair sit-andreach test and back scratch test pre- and post-WBV training. After completing the initial assessment, participants performed squats, calf raises, tricep extensions, and bicep curls on the WBV platform three times per week for 8 weeks. At week 4 , lunges were added to the participants' exercise regimen. Both upper and lower body flexibility increased significantly from 0 to 8 weeks. Although the two aforementioned articles studied flexibility somewhat indirectly, results suggest WBV can be a very promising intervention to maintain or regain flexibility. This is noteworthy considering that flexibility can decline by up to $50 \%$ in certain joints by age 70 [12]. Based upon the search of the literature, these are the only two studies that tested a component of flexibility, indicating a vast potential to examine the effects of targeted flexibility exercises using WBV.

\section{Upper body studies}

Along with flexibility, upper body studies are one of the least established areas of WBV research with older adults. Bissonnette and colleagues [3] are the sole investigators of the 27 articles to examine upper body strength. Nineteen participants (60-85 years) were tested on upper body strength at baseline and after 4 and 8 weeks of training by performing a standardized arm curl test. Following their initial assessment, participants performed static WBV tricep extensions and bicep curls three times per week for 8 weeks. 
Following training participants could lift 49\% more weight compared to baseline performance, on average. This implies meaningful improvement in upper body strength can be attained from WBV exercises targeting those specific muscles [3].

\section{Randomized controlled trials}

Of the $27 \mathrm{WBV}$ studies examining older adults, 19 were randomized controlled trials (RCTs). Components most frequently examined were muscular strength (nine studies) and balance (seven studies). Other variables measured included muscular power (five studies), mobility (four studies), and bone mineral density (BMD - three studies). To a lesser extent, RCTs have examined functional capacity, cardiorespiratory fitness, anabolic hormones, electromyographic activity, torque, motor control, and muscle mass.

The nine studies that examined strength all found statistically significant improvements in muscular strength $[1,5,28$, $33,35,36,41,49,51]$, and three studies suggested WBV is as effective as conventional resistance training [5, 41, 49]. Of the seven studies that examined balance, each one found statistically significant improvements in the components measured. WBV exercise increased balance/postural control [4, 7, 13, 37], WBV exercise was more effective than walking to improve balance [19], and WBV exercise was as effective [18] or possibly superior $[37,48]$ to their comparative traditional exercise programs.

Two studies examining BMD revealed increases in the hip [49] and femoral neck [19]. In addition, Russo et al. [42] found the decline of cortical BMD tended to be less in the WBV group than the control group. Of the three studies that examined BMD, there were no reported adverse effects due to treatment, with the exception of one participant who complained of knee pain [42]. Therefore, WBV may be a viable alternative for individuals who have low BMD, although Totosy de Zepetnek and colleagues [44] have advised caution for individuals suffering from severe osteoporosis. With just three studies specific to adults over 55, this work is clearly in its early stages, and more research is needed prior to providing definitive recommendations for those in this age category who have low BMD or osteoporosis. In the absence of a substantive body of research, caution is warranted.

It is important to note that there were considerable differences in methodologies among the RCTs. Studies ranged from one session to 1 year, participants exercised between two and five times per week and the WBV platform's frequency ranged from 6 to $40 \mathrm{~Hz}$. In addition, there was an underrepresentation of men in the $19 \mathrm{RCT}$ studies. Of the 1,315 individuals who participated in the RCTs, 316 (24.0\%) were men. Therefore, the literature would benefit from replication and/or greater consistency in the methodologies employed, particularly with respect to study duration, the number of weekly exercise sessions, and the hertz utilized.

\section{Limitations and future research}

Although WBV research specific to an older population is relatively new, the evidence suggests that WBV training is a viable option for increasing muscular strength, improving flexibility, improving balance, and reducing the risk of seniors falling. Many of the published studies show that WBV is as effective as resistance training. Readers should be cautioned that this may be due, at least in part, to publication bias; studies with significant findings are more likely find their way into the academic literature. Additionally, the majority of the studies that we reviewed did not mention whether or not the experimenters were blinded when taking measurements. The potential for investigator bias should be controlled for in future studies.

While there are potential limitations, the scientific literature indicates that there is substantial evidence supporting WBV as an effective intervention for older adults, which is important information for seniors who are unable to perform conventional exercise. Additionally, WBV may be appropriate for those with time constraints, as a typical WBV training session takes approximately $15 \mathrm{~min}$, considerably less time than a traditional 45-60 min resistance training regimen. In the studies reviewed, six minutes per body part was the maximum time allotted for WBV training.

Specific vibration platform settings varied significantly from study to study. This can be partially attributed to the different types of WBV platforms used. In addition, researchers have increased the frequency and peak-to-peak displacement of the WBV platform after a few weeks of training to counteract any potential plateau effect $[3,6,26]$. Determining optimal frequency and peak-to-peak displacement settings to maximize results is an important area of future research.

From a practical standpoint, WBV training can be an expensive intervention for the senior population. A vibration platform for home use can cost up to 2,000 euros [52]. Seniors may find it more cost-effective to go to a facility that has an industrial size vibration platform and pay a monthly membership fee. Although, as WBV training for the general public is relatively new, fitness clubs are only beginning to incorporate these devices.

Of the 27 studies that are specific to WBV and the senior population, the primary focus has been on strength or balance components of the lower body. While the results suggest that WBV is effective for lower body muscular strength and postural control, more conclusive evidence is needed to determine if WBV can improve overall flexibility and upper body strength with the aging population, as this area of research is still in its infancy. Ideally, future flexibility and upper body 
strength WBV research would incorporate a randomized controlled study utilizing a WBV group, an exercise without vibration group, and a control group.

\section{References}

1. Bautmans I, Van Hees E, Lemper JC, Mets T (2005) The feasibility of whole body vibration in institutionalised elderly persons and its influence on muscle performance, balance and mobility: a randomised controlled trial. BMC Geriatr 5:1-8

2. Bird ML, Hill K, Ball M, Williams AD (2009) Exercise of resistance- and flexibility-exercise interventions on balance and related measures in older adults. J Aging Phys Act 17:444-454

3. Bissonnette DR, Weir PL, Leigh L, Kenno K (2010) The effects of a whole-body advanced vibration exercise program on flexibility, balance and strength in seniors. Phys Occup Ther Geriatr 28 (3):225-234

4. Bogaerts A, Delecluse C, Boonen S, Claessens AL, Milisen K, Verschueren SMP (2011) Changes in balance, functional performance and fall risk following whole body vibration training and vitamin D supplementation in institutionalized elderly women. A 6 month randomised controlled trial. Gait Posture 33:466-472

5. Bogaerts ACG, Delecluse C, Claessens AL, Troosters T, Boonen S, Verschueren SMP (2009) Effects of whole body vibration training on cardiorespiratory fitness and muscle strength in older individuals (a 1-year randomized controlled trial). Age Ageing 38:448-454

6. Bogaerts A, Verschueren S, Delecluse C, Claessens AL, Boonen S (2007) Effects of whole body vibration training on postural control in older individuals: a 1 year randomized controlled trial. Gait Posture 26:309-316

7. Brogardh C, Flansbjer UB, Lexell J (2010) No effects of wholebody vibration training on muscle strength and gait performance in persons with late effects of polio: a pilot study. Arch Phys Med Rehabil 91(9):1474-1477

8. Bruyere O, Wuidart MA, Di Palma E, Gourlay M, Ethgen O, Richy F, Reginster JY (2005) Controlled whole-body vibration to decrease fall risk and improve health related quality of life of nursing home residents. Arch Phys Med Rehabil 86:303-307

9. Cardinale M, Soiza RL, Leiper JB, Gibson A, Primrose WR (2008) Hormonal responses to a single session of whole body vibration exercise in elderly individuals. Br J Sports Med 44(4):284-288

10. Cardinale M, Wakeling J (2005) Whole body vibration exercise: are vibrations good for you? Br J Sports Med 39:585-589

11. Carlucci F, Mazzà C, Cappozzo A (2010) Does whole-body vibration training have acute residual effects on postural control ability of elderly women? J Strength Cond Res 24(12):3363-3368

12. Chapman E, deVries H, Swezey R (1972) Joint stiffness: effects of exercise on young and old men. J Gerontol 27(2):218-221

13. Cheung WH, Mok HW, Qin L, Sze PC, Lee KM, Leung KS (2007) High-frequency whole-body vibration improves balancing ability in elderly women. Arch Phys Med Rehabil 88:852-857

14. Cochrane DJ, Sartor F, Winwood K, Stannard SR, Narici MV, Rittweger J (2008) A comparison of the physiologic effects of acute whole-body vibration exercise in young and older people. Arch Phys Med Rehabil 89:815-821

15. Delbono O (2003) Neural control of aging skeletal muscle. Aging Cell 2:21-29

16. Delecluse C, Roelants M, Verschueren S (2003) Strength increase after whole-body vibration compared with resistance training. Med Sci Sports Exerc 35:1033-1041

17. DiBrezzo R, Shadden BB, Raybon BH, Powers M (2005) Exercise intervention designed to improve strength and dynamic balance among community-dwelling older adults. J Aging Phys Act 13:198-209

18. Ebersbach G, Edler D, Kaufhold O, Wissel J (2008) Whole body vibration versus conventional physiotherapy to improve balance and gait in Parkinson's disease. Arch Phys Med Rehabil 89:399-403

19. Gusi N, Raimundo A, Leal A (2006) Low-frequency vibratory exercise reduces the risk of bone fracture more than walking: a randomized controlled trial. BMC Musculoskelet Disord 7:92. doi:10.1186/1471-2474-7-92

20. Haas CT, Turbanski S, Kessler K, Schmidtbleicher D (2006) The effects of random whole-body-vibration on motor symptoms in Parkinson's disease. NeuroRehabilitation 21:29-36

21. Janssen I, Heymsfield SB, Wang ZM, Ross R (2000) Skeletal muscle mass distribution in 468 men and women aged 18-88 yr. J Appl Physiol 89:81-88

22. Johnston APW, De Lisio M, Parise G (2008) Resistance training, sarcopenia, and the mitochondrial theory of aging. Appl Physiol Nutr Metab 33:191-199

23. Kawanabe K, Kawashima A, Sashimoto I, Takeda T, Sato Y, Iwamoto J (2007) Effect of whole-body vibration exercise and muscle strengthening, balance, and walking exercises on walking ability in the elderly. Keio J Med 56(1):28-33

24. Leigh L (2008) Balance, falls and whole body vibration training. J Act Aging 7:50-54

25. Lexell J (1995) Human aging, muscle mass, and fiber type composition. J Gerontol Series A Biol Sci Med Sci 50:11-16

26. Liu-Ambrose T, Khan KM, Eng JJ, Lord SR, McKay HA (2004) Balance confidence improves with resistance or agility training. Increase is not correlated with objective changes in fall risk and physical abilities. Gerontology 50(6):373-383

27. Lorenzen C, Maschette W, Koh M, Wilson C (2009) Inconsistent use of terminology in whole body vibration exercise research. J Sci Med Sport 12:676-678

28. Machado A, Garcia-Lopez D, Gonzalez-Gallego J, Garatachea N (2010) Whole body vibration training increases muscle strength and mass in older women: a randomized controlled trial. Scand J Med Sci Sports 20:200-207

29. Marin PJ, Herrero AJ, Sainz N, Rhea MR, Garcia-Lopez D (2010) Effects of different magnitudes of whole-body vibration on arm muscular performance. J Strength Cond Res 24(9):2506-2511

30. McCrory JL, Salacinski AJ, Hunt SE, Greenspan SL (2009) Thigh muscle strength in senior athletes and healthy controls. J Strength Cond Res 23(9):2430-2436

31. Payne VG, Isaacs LD (2008) Human motor development, 7th edn. McGraw-Hill, New York

32. Public Health Agency of Canada (2002) Canada's seniors at a glance. http://www.phac-aspc.gc.ca/seniors-aines. Accessed 25 Sept 2010

33. Raimundo AM, Gusi N, Tomus-Carus P (2009) Fitness efficacy of vibratory exercise compared to walking in postmenopausal women. Eur J Appl Physiol 106:741-748

34. Rauch F, Sievanen H, Boonen S, Cardinale M, Degens H, Felsenberg D, Rittweger J (2010) Reporting whole-body vibration intervention studies: recommendations of the International Society of Musculoskeletal and Neuronal Interactions. J Musculoskelet Neuronal Interact 10(3):193-198

35. Rees S, Murphy A, Watsford M (2007) Effects of vibration exercise on muscle performance and mobility in an older population. J Aging Phys Act 15:367-381

36. Rees SS, Murphy AJ, Watsford ML (2008) Effects of whole-body vibration exercise on lower-extremity muscle strength and power in an older population: a randomized clinical trial. Phys Ther 88 (4):462-470

37. Rees SS, Murphy AJ, Watsford ML (2009) Effects of whole body vibration on postural steadiness in an older population. J Sci Med Sport 12:440-444 
38. Rehn B, Lidström J, Skoglund J, Lindström B (2007) Effects on leg muscular performance from whole-body vibration exercise: a systematic review. Scand J Med Sci Sports 17:2-11

39. Rittweger J (2010) Vibration as an exercise modality: how it may work, and what its potential might be. Eur J Appl Physiol 108 (5):877-904

40. Ritzmann R, Kramer A, Gruber M, Gollhofer A, Taube W (2010) EMG activity during whole body vibration: motion artifacts or stretch reflexes? Eur J Appl Physiol 110:143-151

41. Roelants M, Delecluse C, Verchueren SM (2004) Whole-bodyvibration training increases knee-extension strength and speed of movement in older women. J Am Geriatr Soc 52:901-908

42. Russo CR, Lauretani F, Bandinelli S, Bartali B, Cavazzini C, Guralnik JM, Ferrucci L (2003) High-frequency vibration training increases muscle power in postmenopausal women. Arch Phys Med Rehabil 84:1854-1857

43. Signorile JF (2006) Whole body vibration training: a new wave in exercise intervention for older adults? J Act Aging 5:30-37

44. Totosy de Zepetnek JO, Giangregorio LM, Craven BC (2009) Whole-body vibration as potential intervention for people with low bone mineral density and osteoporosis: a review. J Rehabil Res Dev 46(4):529-542

45. Turbanski S, Haas CT, Schmidtbleicher D, Friedrich A, Duisberg P (2005) Effects of random whole-body vibration on postural control in Parkinson's disease. Res Sports Med 13:243-256
46. US Census (2010) Age data of the United States. http://www. census.gov/population/www/socdemo/age/general-age.html\#older. Accessed 15 Dec 2010

47. van Nees IJW, Geurts ACH, Hendricks HT, Duysens J (2004) Short-term effects of whole-body vibration on postural control in unilateral chronic stroke patients. Am J Phys Med Rehabil 83 (1):867-873

48. van Nees IJW, Latour H, Schils F, Meijer R, van Kuijk A, Geurts $\mathrm{ACH}$ (2006) Long-term effects of 6-week whole-body vibration on balance recovery and activities of daily living in the postacute phase of stroke: a randomized, controlled trial. Stroke 37:2331-2335

49. Verschueren SMP, Roelants M, Delecluse C, Swinnen S, Vanderschueren D, Boonen S (2004) Effect of 6-month whole body vibration training on hip density, muscle strength, and postural control in postmenopausal women: a randomized controlled pilot study. $\mathrm{J}$ Bone Miner Res 19:352-359

50. Veterans Affairs Canada (2009) The facts. http://www.vacacc.gc.ca/ clients/sub.cfm?source=health/fallsp/fallfac. Accessed $30 \mathrm{Jul} 2009$

51. von Stengel S, Kemmler W, Engelke K, Kalender WA (2010) Effect of whole-body vibration on neuromuscular performance and body composition for females 65 years and older: a randomized-controlled trial. Scand J Med Sci Sports. doi:10.1111/j.1600-0838.2010.01126.x

52. WAVE (2010) WAVE Products. http://www.wavexercise.ca/prod ucts.html. Accessed 15 Dec 2010 